giảm tín hiệu không thâyy tín hiệu dịch trong các vòng ốc tai trên CHT. Cả 4 tai này đều không còn chỉ định cây OTĐT chỉ có thể cấy điện cực thân não, không có tai nào cốt hoá độ 1 và độ 2 nên không còn chỉ định cấy OTĐT.

\section{KẾT LUẬN}

Lựa chọn BN để cấy OTĐT phụ thuộc vào nhiêu yếu tố bao gồm sức nghe, mức độ dị dạng ốc tai, tình trạng cốt hoá ốc tai và sự có mặt của dây TK ốc tai. Vì vậy việc đánh giá hình ảnh CLVT và CHT trước phẫu thuật là vô cùng quan trọng. Những BN có giải phẫu ốc tai bình thường, dị dạng nhệ ốc tai vẫn có thể đưa được điện cực vào ốc tai, chỉ định cây OTĐT phụ thuộc và sự có mặt của dây TK ốc tai trên CHT hoặc đáp ứng âm thanh trên thính lực. Các di dạng nặng ốc tai, cốt hoá nặng ốc tai không thể đưa được điện cực vào ốc tai, không có dây TK ốc tai trên hình ảnh, không có đáp ứng âm thanh trên thính lực thì không thể cấy OTĐT chỉ có thể cấy điện cực thân não.

\section{TÀI LIÊU THAM KHẢO}

1. Sennaroğlu, L. and Bajin, M.D. (2017). Classification and Current Management of Inner Ear Malformations. Balkan medical journal, 34(5): p. 397.

2. Agarwal, S.K., Singh, S., Ghuman, S.S., et al (2014). Radiological assessment of the Indian children with congenital sensorineural hearing loss. International journal of otolaryngology, 2014

3. Raghunandhan, S., Madhav, Senthilvadivu, A., et al (2019). 'Paediatric auditory brainstem implantation: The South Asian experience. European annals of otorhinolaryngology, head and neck diseases, 136(3): p. S9-S14.

4. Cinar, B.C., Batuk, M.O., Tahir, E., et al (2017). Audiologic and radiologic findings in cochlear hypoplasia. Auris Nasus Larynx, 44(6): p. 655-663.

5. Sampaio, A.L., Araujo, M.F., and Oliveira, C.A. (2011). New criteria of indication and selection of patients to cochlear implant. Int J Otolaryngol, 2011: p. 573-968.

6. Han, J.J., Suh, M.-W., Park, M.K., et al (2019). A Predictive Model for Cochlear Implant Outcome in Children with Cochlear Nerve Deficiency. Scientific reports, 9(1): p. 1154.

7. Buchman, C.A., Teagle, H.F., Roush, P.A., et al (2011). Cochlear implantation in children with labyrinthine anomalies and cochlear nerve deficiency: implications for auditory brainstem implantation. Laryngoscope, 121(9): p. 1979-88.

8. Zhang, L., Qiu, J., Qin, F., et al (2017). Cochlear implantation outcomes in children with common cavity deformity; a retrospective study. Journal of otology, 12(3): p. 138-142.

9. Booth, T.N., Roland, P., Kutz, J.W., Jr., et al (2013). High-resolution 3-D T2-weighted imaging in the diagnosis of labyrinthitis ossificans: emphasis on subtle cochlear involvement. Pediatr Radiol, 43(12): p. 1584-90.

\title{
ĐÁNH GIÁ KẾT QUẢ PHỤC HỒI CHỨC NĂNG VÂ̂N ĐộNG CHI TRÊN Ở BÊNH NHÂN LIỂT NỬA NGƯờI DO NHỒI MÁU NÃO BẰNG GĂNG TAY ROBOT GLOREHA
}

\section{TÓM TẮT \\ Mục tiêu: Đánh giá kết quả phục hồi chức năng vân động chi trên ở bệnh nhân liệt nửa người do nhồi máu não bằng Găng tay robot Gloreha tại Bệnh viện Điều dưỡng Phục hồi chức năng Trung Ương năm 2020 - 2021. Đối tượng và phương pháp: Nghiên cứu can thiệp lâm sàng trên 32 bệnh nhân liệt nửa người do nhồi máu não bằng chương trình găng tay robot Gloreha. Đánh giá kết quả phục hồi chức năng chi trên sau 3 tuần và 6 tuần bằng chỉ số chức năng chi trên Fulg Meyer Arm Test và thang điểm vận động bàn tay HMS. Kết quả: Nhồi máu não gặp ở người cao tuổi $>60$ tuổi chiếm tỷ lệ cao nhất $(56,2 \%)$, không}

*Bệnh viện Điều dưỡng Phuc hồi chức năng Trung Ương **Trướng Đai học Y Hà Nôii

Chịu trách nhiệm chính: Phạm Văn Minh

Email: pvminhrehab@yahoo.com

Ngày nhận bài: 21.6.2021

Ngày phản biên khoa hoc: 16.8 .2021

Ngày duyệt bài: 24.8.2021
Lê Huy Cường*, Phạm Văn Minh** có sự chênh lệch đáng kể giữa hai nhóm bệnh nhân có rổi loạn cảm giác và không có rối loạn cảm giác, tỷ lệ bệnh nhân có mức vận động khá và tốt sau 3 tuần và sau 6 tuần tăng rõ rệt, khác biệt có nghĩa thống kê sau 6 tuần $(p<0,05)$. Kết luận: Phục hồi chức năng vận động bàn tay bằng găng tay robot có kết quả tốt sau 6 tuần điều tri.

Tứ khóa: Nhồi máu não, phục hồi chức năng, găng tay robot Gloreha

\section{SUMMARY}

\section{ASSESSMENT OF THE RESULTS OF RECOVERY MOTOR FUNCTION UPPER LIMB IN PATIENTS WITH HEMIPLEGIA DUE TO ISCHEMIC}

STROKE BY ROBOT GLOVES GLOREHA

Objective: To evaluate the results of upper extremity motor rehabilitation in patients with hemiplegia due to ischemic stroke using Gloreha Robotic Gloves at the National Hospital of Sanatorium and Rehabilitation in 2020 - 2021. Subjects and methods: Clinical intervention study on 32 patients 
with hemiplegia due to ischemic stroke using Gloreha robotic glove program. Evaluation of the results of upper limb rehabilitation after 3 weeks and 6 weeks by Fulg Meyer Arm Test (FMA) upper limb function index and Hand Motor Scale (HMS). Results: Ischemic stroke in the elderly >60 age accounted for the highest rate $(56.2 \%)$, there was no significant difference between the two groups of patients with and without sensory disturbances. The percentage of patients with good and very good mobility after 3 weeks and after 6 weeks increased significantly, the difference was statistically significant after 6 weeks $(p<0.05)$. Conclusion: rehabilitation of hand motor function with robotic gloves has good results after 6 weeks of therapy.

Keywords: Ischemic stroke, rehabilitation, robot gloves Gloreha

\section{I. ĐĂT VẤN ĐỀ}

Đột quy não là môtt vấn đề sức khỏe lớn của mọi quốc gia trên thế giới. Theo công bố của Tổ chức $Y$ tế Thễ giới, đôt quy não là môt trong những bệnh lý hàng đầu và là nguyên nhân gây tử vong đứng hàng thứ ba sau bệnh ung thư và tim mạch. Bệnh có thể gây tử vong nhanh chóng hoặc để lại nhiều di chứng nặng nề, nhất là di chứng về vận động, trong đó di chứng làm giảm và mất vận động của chi trên chiếm tî lệ lớn. Khoảng $80 \%$ người sông sót sau đột quỵ biểu hiên suy giảm vận động liên quan đền chi trên. Mức độ vận động của chi trên là tương quan với các hoạt động cơ bản của cuộc sống hàng ngày $(A D L)$ cũng như sự tham gia hòa nhập vào xã hội sau đột quy [1] [2].

Chính vì vậy, cải thiện chức năng vận động của chi trên là mục tiêu vô cùng quan trọng trong phục hồi chức năng sau đột quy nhằm nâng cao chất lượng cuộc sống cho người bệnh. Các phương pháp hoạt động trị liệu nói chung cũng như phương pháp CIMT đang phổ biến được áp dụng hiện nay đòi hỏi bệnh nhân cần có những vận động chủ động một phần cổ tay và các ngón tay của tay bên liệt trong khi ưu điểm lớn nhất của phương pháp sử dụng găng tay robot là có thể áp dụng ngay cả khi tay bên liệt bị liệt hoàn toàn.

Các hệ thống robot có nhiều đặc tính, như độ lặp lại cao, khả năng thực hiện một số lượng lớn các bài tập trong một phiển dưy nhất và cường độ cao của đào tạo theo định hướng nhiệm vụ. Phương pháp sử dụng găng tay robot đã được nhiêu tác giả nghiên cứu áp dụng trên thế giới và đã được chứng minh là có hiệu quả rõ rệt trong việc cải thiện chức năng chi trên [3] [4]. Tuy nhiên tại Việt Nam chưa có nhiêu nghiên cứu về vẫn đề này. Do vậy chúng tôi tiến hành nghiên cứu đề tài trên nhằm: Đánh giá kết quả phưc hồi chức năng vận động chi trên ở bệnh nhân liệt nửa người do nhồi máu não bằng Găng tay robot Gloreha tại Bệnh viện Điều dưỡng Phục hồi chức năng Trung Ương năm 2020-2021.

\section{II. ĐỐI TƯƠNGG VÀ PHƯƠNG PHÁP NGHIÊN CỨU}

2.1. Đối tượng nghiên cứu

2.1.1. Tiêu chuẩn lựa chọn

- Bệnh nhân được chẩn đoán liệt nửa người do nhồi máu não lần đầu

- Bệnh nhân ở giai đoạn hồi phục (sau 24h-6 tháng).

- Bệnh nhân có phim chụp CT Scanner hoặc MRI sọ não có hình ảnh của nhồi máu não

- Chi bên liệt bị liệt không hoàn toàn có thể nâng được vai.

- Bệnh nhân hoàn toàn tỉnh táo và có mức độ đột quy theo thang điểm NIHSS nhẹ, vừa (điểm NIHSS 1-15)

- Bệnh nhân ngồi vững, thăng bằng ngồi tốt

- Độ co cứng bàn tay liệt theo Asworth cải biên dưới 3

- Tuổi từ 18 trở lên.

- Đồng ý tham gia nghiên cứu và tuân thủ qui trình tập luyện.

\subsubsection{Tiêu chuẩn loại trừ}

- Liệt nửa người do các nguyên nhân không phải nhồi máu não.

- Có khuyết tật về vận động chi bên liệt trước khi bị đột quy.

- Có mắc các bệnh lý động kinh, tim mạch không ổn định.

- Bị đột quy. hoặc tử vong trong thời gian nghiên cứu.

-Không đồng ý tham gia nghiên cứu.

2.2. Phương pháp nghiên cứu

2.2.1. Thiêt kế nghiên cứu. Nghiên cứu can thiệp lâm sàng đối chứng trước sau điều trị bằng chương trình găng tay robot Gloreha trên hệ thống Găng tay robot Gloreha Profession 2 với màn hình mô phỏng 3D bao gồm: Tập vận động theo tầm vận động khớp chi trên, tập co duỗi các ngón taỳ, tập đối chiếu ngón, tập cầm nắm đồ vầt (ống nhứa, khối nhỏ hình vuông), liẹu trình 5 ngày/ tuần, 2 giờ tâp/ngày, chia 2 phiên sáng, chiều. Phân tích và đánh giá kết quả sau 3 tuân và sau 6 tuần.

2.2.2. Chọn mẫu và cỡ mẫu. Cỡ mẫu gồm 32 bệnh nhân đáp ứng đầy đủ các tiêu chuẩn lựa chọn được đưa vào nghiên cứu.

Phương pháp chọn mẫu: Lấy cỡ mẫu thuận tiên

2.2.3. Các biến số và chỉ tiêu đánh giá: Tuổi, giới tính, thời gian mắc bệnh, bên liệt, mức 
độ vận động chi trên bên liệt thông qua thang điểm FMA và HMS.

2.2.4. Thu thập và xử lý số liệu. Kết quả lượng giá và điều trị được ghi chép vào phiếu

\section{KẾT QUẢ NGHIÊN CỨU}

\section{1. Đặc điểm đối tượng nghiên cứu}

Bảng 3.1. Theo nhóm tuổi.

\begin{tabular}{|c|c|c|c|c|c|c|}
\hline \multirow{2}{*}{ Tuổi Giới tính } & \multicolumn{2}{|c|}{ Nam } & \multicolumn{2}{c|}{ Nữ } & \multicolumn{2}{c|}{ Tổng } \\
\cline { 2 - 7 } & Số BN & Tỷ lệ \% & Số BN & Tỷ lệ \% & Số BN & Tỷ lệ \% \\
\hline$<40$ & 1 & 3.1 & 2 & 6.2 & 3 & 9.4 \\
\hline $40-49$ & 0 & - & 4 & 12.5 & 4 & 12.5 \\
\hline $50-59$ & 5 & 15.6 & 2 & 6.2 & 7 & 21.8 \\
\hline $60-69$ & 5 & 15.6 & 6 & 18.8 & 11 & 34.3 \\
\hline$\geq 70$ & 7 & 21.8 & 0 & - & 7 & 21.8 \\
\hline Tống & $\mathbf{1 8}$ & $\mathbf{5 6 , 2}$ & $\mathbf{1 4}$ & $\mathbf{4 3 , 7}$ & $\mathbf{3 2}$ & $\mathbf{1 0 0}$ \\
\hline
\end{tabular}

Nhận xét: Bảng 3.1 cho thấy đột quy não gặp ở người cao tuối $>60$ chiếm tỷ lệ cao nhất $(56,2 \%)$

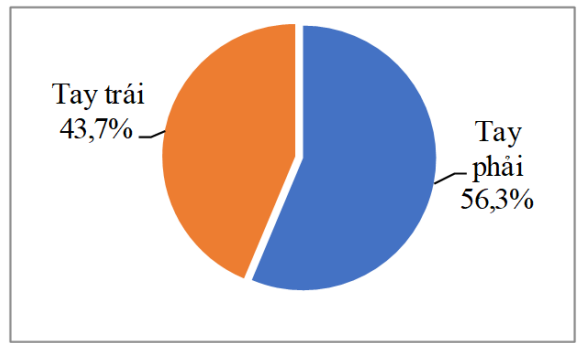

Biểu đồ 3.1. Theo bên bi liêt.

Nhân xét: Tỷ lệ bệnh nhân liệt tay phải (56,3\%) cao hơn tay trái.

Bảng 3.2. Theo thời gian bi bênh đến khi được phục hồi chức năng

\begin{tabular}{|c|c|c|}
\hline $\begin{array}{c}\text { Thời gian bị bệnh } \\
\text { đến khi PHCiN }\end{array}$ & $\begin{array}{c}\text { Số beểnh } \\
\text { nhẩn }\end{array}$ & $\begin{array}{c}\text { Tỷ leê } \\
\mathbf{( \% )}\end{array}$ \\
\hline$<2$ tuần & 2 & 6,2 \\
\hline 2 tuần -1 tháng & 8 & 25,0 \\
\hline $1-3$ tháng & 14 & 43,8 \\
\hline$>3$ tháng & 8 & 25,0 \\
\hline Tống & $\mathbf{3 2}$ & $\mathbf{1 0 0}$ \\
\hline
\end{tabular}

Nhận xét: Tỷ lệ bệnh nhân được can thiệp PHCN sớm trong vòng 2 tuần chiếm tỷ lệ rất ít $(6,2 \%)$. đánh giá ở thời điểm trước và sau điều trị. Xử lý số liệu bằng phần mềm SPSS 20.0.Tính tỷ lệ \% trung bình công. Kiểm đinh $X^{2}$ so sánh 2 biến tỷ lệ với $p<0,05$ được xem là khác biệt có ý nghĩa.$$
\text { . }
$$

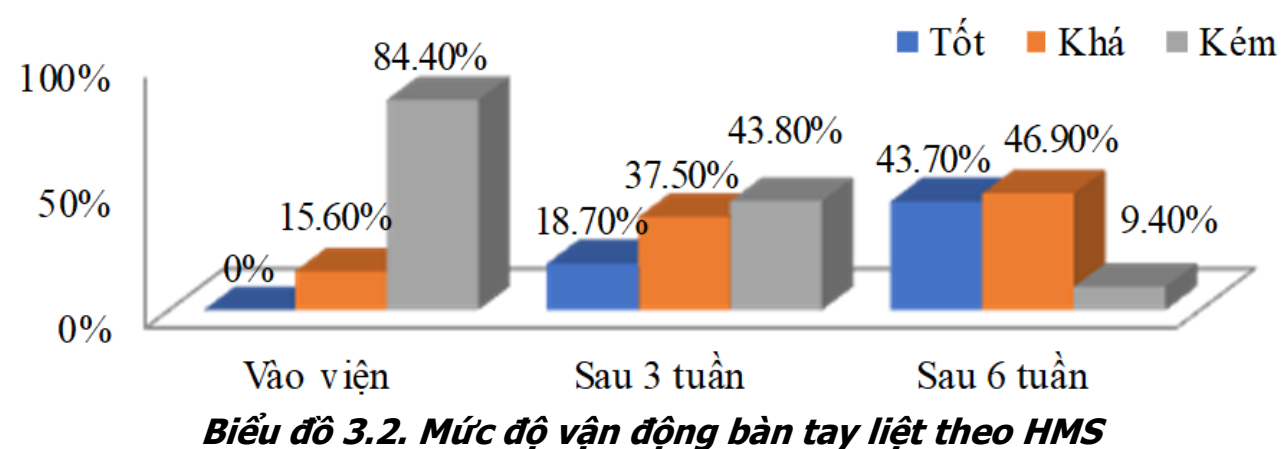

Nhận xét: Tỷ lệ bệnh nhân có mức vận động khá và tốt sau 3 tuần và sau 6 tuần tăng rõ rệt, khác biệt có nghĩa thống kê $(p<0,05)$. 


\section{BÀN LUẬN}

4.1. Đặc điểm đối tượng nghiên cứu

- Độ tuổi và giới tính. Nghiên cứu của chúng tôi có 32 bệnh nhân với 18 nam (56,3\%) và 14 nữ $(43,7 \%)$, tuổi thấp nhất là 27 tuổi và cao nhất là 80 tuổi. Độ tuổi trên 60 chiếm tỷ lệ cao nhất, kết quả nghiên cứu này cũng phù hợp với Trần Văn Chương và Lê Đức Hinh [5] [6]. Nhìn chung tất cả các nghiên cứu đều chỉ ra rằng đột quy hay gặp ở nam nhiều hơn nữ.

- Bên liệt và tình trạng rối loạn cảm giác, thời gian đến phục hồi chức năng. Nghiên cứu của chúng tôi gặp số bệnh nhân liệt tay phải và tay trái là khác nhau (tay phải chiếm $56,3 \%)$. Sự khác biệt này có lẽ do cõ mẫu trong nghiên cứu của chúng tôi còn ít.

Trong số 32 bệnh nhân nghiên cứu, chỉ có 2 bệnh nhân được phục hồi chức năng trong vòng 2 tuần tính từ khi bị đột quỵ đây là những bệnh nhân chuyển tuyến ngay sau khi điều trị giai đoạn cấp từ cấp cứu và thần kinh. Có tới $68,8 \%$ số người bệnh được phục hồi chức năng sau 1 tháng đột quy, đa phần bệnh nhân về nhà rồi mới đến cơ sở phục hồi chức năng. Chính vì điều đó làm giảm sự tỷ lệ hồi phục mặc dù được can thiệp phục hồi chức năng tích cực.

Trong 32 bệnh nhân chúng tôi gặp 15 bệnh nhân có tình trạng rối loạn cảm giác tay bên liệt (chiếm 53,1\%), thông thường sau đột quy. có nhiều khiếm khuyết, trong đó khiếm khuyết về cảm giác làm cản trở quá trình tham gia phục hồi vận động tay liệt. Theo Borboni $A$ [7] thì trị liệu trên găng tay robot có thể làm giảm các co cứng ở tay, cổ tay cũng như làm giảm các rối loạn cảm giác đau ở tay liệt. Trong nghiên cứu của chúng tôi chưa có điều kiện đánh giá sự thay đổi các rối loạn cảm giác và co cứng ở bàn tay liệt sau thời gian trị liệu. Tuy nhiên chúng tôi nhận thấy mức độ rối loạn cảm giác là không nhiều.

4.2. Kết quả phục hồi chức năng bàn tay bằng găng tay robot Gloreha.

- Kết quả phục hồi chức năng vận động chi trên theo FMA. Bảng 3.4 cho thấy tỷ lệ bệnh nhân có mức độ chức năng tay liệt trung bình và kém là chủ yểu chiếm tới $71,9 \%$, không có bệnh nhân có mức độ chức năng tay liệt tốt. Tỷ lệ này giảm xuống đáng kể còn $59,4 \%$ sau 3 tuần và còn $37,5 \%$ sau can thiệp 6 tuần. Trong khi đó số bệnh nhân có điểm FMA tốt sau 3 tuần là 4 và tăng lên 8 sau 6 tuần. Tỷ lệ bệnh nhân có điểm FMA khá cũng cải thiện đáng kể sau thời gian trị liệu. Tuy nhiên kết quả chỉ có ý nghĩa thống kê $(p<0,05)$ sau 6 tuần. Điều này cũng phù hợp với các tác giả khác như Jorge $\mathrm{H}$ và $\mathrm{CS}$
[8] lại thấy sau 3 tuần chức năng vận động tay theo thang điểm QuickDASH, Barthel, VAS đều cải thiện rõ, không những vậy nghiên cứu còn chỉ ra rằng găng tay robot cò̀ là phương pháp điều trị tốt cho việc kiểm soát đau và co cứng ở bệnh nhân đột quỵ. não.

- Kết quả phục hồi chức năng theo HMS. Trong 32 bệnh nhân nghiên cứu khi vào viện hầu hết đều có mức vận động bàn tay kém (1-2) rất ít bệnh nhân đạt mức khá và tốt. Tuy nhiên sau 3 tuần tỷ lệ bệnh nhân có điểm vận động bàn tay mức kém đã giảm từ $84,4 \%$ xuống còn $43,0 \%$ và sau 6 tuần tỷ lệ này chỉ còn $8,4 \%$ trong khi đó tỷ lệ bệnh nhẩn có mức vận động khá tăng từ $5,6 \%$ khi vào viện lên $37,5 \%$ sau 3 tuần và lên $43,0 \%$ sau 6 tuần. Sự khác biệt này có nghĩa thống kê $(p<0,05)$.

Jakub $P$ và $C S$ [4] nghiên cứu 33 bệnh nhân bằng liệu pháp robot bàn tay sau 26 tuần thây có sự cải thiện chức năng vận động các ngón tay từ 20 lên 25 điểm. Fabio $V$ và CS [3] nghiên cứu trên 30 bệnh nhân đột quy. có chỉ số co cứng Asworth dưới 3 , đánh giá chức năng bàn tay liệt theo thang điểm Nine Hole Peg Test thây sự cải thiện rõ rệt $(p=0,002)$. Kết quả nghiên cứu của các tác giả khác cũng đi đến thống nhất có sự cải thiện chức năng vận động bàn tay sau 3-4 tuần cho dù các nghiên cứu dùng các thang điểm đánh giá khác nhau.

\section{KẾT LUẬN}

Kết quả đánh giá phục hồi chức năng bàn tay trên 32 bệnh nhân nhồi máu não bằng găng tay robot Gloreha như sau:

- Tuổi hay gặp đột quỵ não là trên 60 tuổi, tuổi thấp nhất là 28 , cao nhất là 80 . Tỷ lệ nam nhiều hơn nữ.

- Chức năng vận động bàn tay liệt cải thiện rõ rệt sau 6 tuần can thiệp với găng tay robot Gloreha.

\section{TÀI LIÊU THAM KHẢO}

1. Langhorne $P$, Alex Coupar F Fau - Pollock và A. Pollock (2009), Motor recovery after stroke: a systematic review. Lancet Neurol, 8 (8), 741-754.

2. Veerbeek JM, Erwin EH. et al (2011), Early prediction of outcome of activities of daily living after stroke: a systematic review. Stroke, 42 (5), 1482-1488.

3. Fabio V, Palmira B (2016 ), Feasibility and efficacy of a robotic device for hand rehabilitation in hemiplegic stroke patients: A randomized pilot controlled study. Clinical Rehabil, 1-10.

4. Jakub Petioky, Krasova, Mikulenkova Petra (2016), Robotic glove with virtual biofeedback in spacicity management on acute and chronic patients with spastic hand paresis: impact on goal oriented functional therapy and routine mass therapy. $20^{\text {th }}$ congress of physical and 
rehabilitation medicine, 454-458.

5. Lê Đức Hinh và CS (2008), Tai biến mạch máu não. Nhà xuất bản Y hoc, 29 - 47

6. Trân Văn Chương (2010), Phục hồi chức năng bênh nhân liêt nửa người do tai biến mach máu nã̃o, Vật lý trị liệu - Phục hồi chức năng. Nhà xuất bản Y học Hà Nội, 574 - 603.
7. Borboni A, Mor M, Faglia R (2016), Gloreha hand robotic rehabilitation : design, medical model and experiments. J Dyn Syst Meas control, 138.

8. Jorge H, Giovanni T, Silvia G (2015), Efficacy of short-term robot-assisted rehabilitation in patients with hand paralysis after stroke: A randomized clinical trial. AAHS, Hand, 1-8.

\section{KIẾN THỨC, THỰC HÀNH VÀ CÁC YẾU TỐ LIÊN QUAN VỀ PHÒNG CHỐNG BÊNH HO GÀ CỦA CÁC BÀ ME Có CON DƯớI 5 TUỔI TÅI TỈNH NAM ĐINNH NĂM 2020}

\section{TÓM TẮT}

Nghiên cứu mô tả cắt ngang được thực hiện trên 384 bà me có con dưới 5 tuổi nhằm mô tả thực trang và các yểu tố liên quan đến kiến thức, thức hành phòng chống bệnh ho gà của các bà mẹ tại tỉnh Nam Định từ tháng $9 / 2020$ đến tháng $5 / 2021$. Kết quả nghiên cứu cho thấy: Tỷ lệ bà mẹ đạt kiến thức chung về phòng bệnh ho gà thấp $(28,9 \%)$, tuy nhiên tỷ lệ bà mẹ đạt thực hành phòng bệnh ho gà khá cao $(70,6 \%)$. Các yếu tố liên quan tới kiến thức của bà me là: địa điểm sinh sống, số con của bà mẹ và tiếp cận được nguồn thông tin truyền thông về ho gà. Nghiển cứu có tìm thấy mối liên quan có ý nghĩa thống kê giữa thực hành với nơi ở và trình độ học vấn. Công tác truyền thông, giáo dục sức khoẻ cần phải được tăng cường hơn nữa, lựa chọn các phương pháp truyền thông phù hợp, thời điểm truyên thông thích hợp, nâng cao trình độ cho cán bộ y tế cơ sở giúp nâng cao kiến thức, thực hành phòng bệnh của các bà mẹ.

Tư khóa: bệnh ho gà, kiến thức, thực hành

\section{SUMMARY}

THE SITUATION AND RELATED FACTORS TO KNOWLEDGE AND PRACTICE OF PERTUSSIS PREVENTION AMONG MOTHERS WITH CHILDREN UNDER 5 YEARS OLD IN NAM DINH PROVINCE FROM SEPTEMBER 2020 TO MAY 2021

A cross - sectional descriptive study was conducted on 384 mothers with children under five years of age to describe the situation and some factors related to knowledge and practice of pertussis prevention from September 2020 to May 2021. The results showed that: The percentage of mothers who had good general knowledge about preventing pertussis disease is low $(28.9 \%)$, but the prevalence of good practice of mothers about pertussis prevention is quite high $(70.6 \%)$. Related factors to mother's knowledge are:

*Trường Đại hơ Y Dược Thái Binh

Chịu trách nhiệm chính: Ngô Văn Mạnh

Email: manhsdh@gmail.com

Ngày nhận bài: 17.6.2021

Ngày phản biên khoa hoc: 16.8.2021

Ngày duyệt bài: 24.8.2021
Ngô Văn Mạnh*, Bùi Thị Huyền Diệu*

place of residence, number of children and access to media information about pertussis. The study found a statistically significant association between practice and residence and educational attainment. Health communication and education need to be further strengthened, choosing appropriate communication methods, appropriate communication time, improve the qualifications of local health workers,... to help improve knowledge and practice prevention of mothers.

Keywords: pertussis; knowledge; practic

\section{I. ĐĂT VẤN ĐỀ}

Bệnh ho gà là môt truyền nhiễm cấp tính đường hô hấp, có thể gây ra các biến chứng nghiêm trọng, rất dễ lây tữ người sang người và thường xảy ra ở trẻ nhỏ. Mặc dù bênh đã có vắc xin dự phòng nhưng bênh vẫn chưa hoàn toàn được kiểm soát và có thể gây tử vong. Tổ chức $y$ tế thế giới $(\mathrm{WHO})$ ước tính, hàng năm vẫn có 24 triệu ca mắc ho gà trên toàn thế giới và gây nên khoảng 160.700 ca tử vong, phần lớn trong số đó là trẻ dưới 5 tuổi[1]. Trên thế giới năm 2018 vẫn còn 151.074 ca mắc; năm 2019 tỷ lê bao phủ vắc xin bach hầu-ho gà-uốn ván (DPT) mũi 3 mới chỉ đạt $85 \%$ [2]. Tại Việt Nam sau nhiều năm tiêm vắc xin DPT, tỷ lệ mắc và chết của bênh ho gà đã giảm rất rõ rệt. Tỷ lệ mắc hàng năm dao động từ 0,059-1,78 trên 100.000 dân. Sau khi giảm vào năm 2004, số ca mắc đã được báo cáo ngày càng tăng kể từ năm 2015. Tích Iũy năm 2019, cả nước ghi nhận 1.227 trường hợp mắc ho gà, 01 trường hợp tử vong. So với năm 2018 tỷ lệ mắc là $0.43 / 100.000$ dân (676 trường hợp mắc, 02 tử vong), số mắc tăng $81,5 \%[3],[4],[5]$.

Để phòng chống bệnh ho gà thì việc hiểu biết và thực hiện tốt của người dân nói chung và của các bà me nói riêng về phòng chống bệnh ho gà sẽ góp phần rất lớn trong công tác phòng chống dịch. Tuy nhiên trên thực tế, không phải toàn bộ cha/ mẹ/ người chăm sóc chính đều có kiến 